cién llegaba a imponerse al ambiente cultural provinciano. Y sólo cuando más tarde se le dio el Premio Nóbel fue su obra revisada y considerada en gran medida. Yo nunca la lei por una especie de rechazo fundamentado en la misma insistencia con que se recomendaba su genio. Fuéronme también totalmente desconocidos, hasta hace poco tiempo, tanto Neruda como el resto de los poetas que le suceden, cuya obra y cuyos nombres no nos fueron nunca propuestos. $\mathbf{Y}$ deberín ustedes creerme que por lo menos hasta hace dos años, en que la llegada de nuevos elementos al profesorado cambió el panorama cultural-literario del Liceo de Hombres, los idolos literarios continuaban siendo Núnez de Arce, Ramón de Campoamor y Víctor Domingo Silva, entre los chilenos, con un desconocimiento absoluto de los grandes valores poéticos.

No me fueron, sin embargo, desconocidas las poetisas uruguayas y argentinas. Admiré en forma sucesiva a la Ibarbourou, a la Agustini y a la Storni, a través de lecturas particulares. A la salida del colegio me lancé abierta y desordenadamente al encuentro de novelistas como Hesse, Thomas Mann, Wassermann, Steinbeck y más tarde Dostoiewski, Joyce y Proust, cuyo aporte considero importantísimo y determinante en mi formación literaria.

Paralelamente a estas lecturas, comienzo a tomar contacto con personas profundamente interesadas en la cosa poética; conozco poetas y escritores con quienes mantengo largas conversaciones sobre lo humano y lo divino, como diria Violeta Parra: viajo, amo, veo.

En el corazón de mi provincia formamos, con dos poetas amigos, un verdadero mundo poético para nuestro uso exclusivo, rico en vivencias, al cual contribuyen tres o cuatro amigos más que se mueven en esta órbita.

\title{
Claudio Solar
}

\section{AQUI Y AHORA EN LA LITERATURA CHILENA}

SOY onservador $y$, como tal, sólo pretendo dejar constancia de ciertos puntos o aspectos observados en este 20 Encuentro de Escritores, en torno a la Literatura Chilena.

Ha sido común, entre Europa y América, cierto constante fenómeno de discronía. Mientras en Europa el romanticismo da paso a otras tendencias, la calidad romántica se impone en Amériça. Cuạdo el surrea- 
lismo estalla en crisis decadente y se parcela en otras tendencias europeas, en Chile se le impone como novedad. En un comienzo se produce el desequilibrio entre manera (forma) y materia (contenido). Así, en Pedro de Oña, su forma es renacentista y el contenido americano.

Este fenómeno de discronía no quiere decir, en absoluto, que tengamos, necesariamente, que seguir el proceso europeo. En varias oportunidades, en especial en poesía, les hemos impuesto ya el creacionismo huidobriano - la cordillera nerudiana con su dicción inconfundible. De donde entendemos que las culturas de occidente $y$ oriente no son más que partes de una sola unidad que es el acervo cultural humano.

La presencia de la realidad chilena en nuestra literatura, aunque con formas ajenas, va a indicar con su "Araucana" la iniciación de algo auténtico y nacional.

Fijación de nuestra nacionalidad.-La literatura del siglo veinte prosigue la misma finalidad que la generación de la Independencia: la fijación de nuestra nacionalidad. Para que exista una nacionalidad efectiva, es necesaria la independencia de suelo, la existencia de una economía propia y una lengua común a esta nacionalidad.

Una Literatura de acuerdo con esta nacionalidad ha de tender a fijar sus costumbres, sus luchas, el carácter de su gente, su idiosincrasia. Tal tendencia no puede ser otra que aquella que engendra el realismo. Entendemos por realismo el equilibrio entre forma y contenido. Cuando se exagera el contenido en desmedro de su forma, la obra artistica sufre menoscabo y se convierte en una subliteratura de ideas; cuando la preocupación sólo está dirigida a la forma, se cae cn el evasionismo, en un mero afán esteticista.

Nacimos a la Literatura con “La Araucana”, de Ercilla. Y aún podríamos decir que con Pedro de Valdivia en sus Cartas a Carlos V, pues con él se inicia el tema de la tierra y su gente, que ha de ser materia de todos nuestros autores. Se continúa con las crónicas del Padre Ovalle y con Pineda y Bascuñán.

Luego viene la generación de la Independencia influida por los enciclopedistas franceses: "Don Juan Egaña y Camilo Henríquez juraban por Voltaire, Montesquieu y Rousseau como por la Santísima Trinidad".

Tras el colapso siguiente, surge la generación del 42. Su importancia resicle en su actitud critica frente a la tendencia europeizante.

Luego vienen los Costumbristas y la generación del 91 . Jotabeche y Lastarria hạ ṣiḍo los iṇiçiạdores dẹ çuẹntọ chilenon. Perọ son Pérẹz 
Rosales y Blest Gana quienes van a retratar su siglo. Blest Gana realiza la crítica a la aristocracia minera en decadencia; muestra el nacimiento de la clase media - la de medio pelo-. La revolución del 91 cierra una etapa e inicia otra. Se desmoralizó la clase alta declinante y se sumó a ésta la desmoralización de la burguesía arribista. Luis Orrego Luco es el escritor de esta época. Pero quien surge de ella y se impone más tarde como un valor universal, en esta ruina de valores, es Augusto D'Halmar. Introduce la lectura de Tolstoy, Gorki, Andersen, Dickens, Maupassant. Se inicia con una obra realista, más luego derivará hacia las obras de imaginación.

La Generación del 900 reaccionó contra la hiperestesia; no más biombos de laca, pájaros chinos, elementos ajenos a la avifauna americana. Nace la conciencia de lo nacional y una actitud: la actitud social que engendra la conciencia social. Baldomero Lillo, sin poseer una línea de consignas en su obra, realiza la más intensa literatura social con un lenguaje vigoroso, ajustado, funcional, revelando la vida minera. Lo hace con más precisión que su contemporáneo Federico Gana, quien cuenta la vida campesina; Lillo bajó a los infiernos: Gana fue sólo el patrón que se paseó por los fundos. Sin embargo, esta es la fuerte y recia partida del criollismo.

El criollismo es la tendencia que muestra en sus obras la tradición, la vida, las gentes, el lenguaje - tanto del campo, como de la ciudad-; es decir, se trata siempre del realismo. Cuestión de etiqueta. Fue Alone quien, al juzgar las primeras etapas de los criollistas y observando su tendencia campesina, circunscribió el criollismo a la literatura campestre.

La recia partida del criollismo la integraron, además, Antonio Bórquez Solar, Carlos Acuña, Diego Dublé Urrutia, Samuel A. Lillo y Carlos Pezoa Véliz entre los poetas.

El criollismo -o realismo- debe ser considerado también bajo los puntos de vista expuestos en el hacer poético. Pero no es posible, en este breve trabajo, hacer un análisis de este fenómeno tan complejo que ha sido la poesia en Chile. Baste decir que "Nada" con su visión de personajes populares - “el vagabundo que comía poco", "el chusco que oía las conversaciones", "la chica y el panteonero"- muestra auténticos personajes de cierta realidad populista. Al igual que en "Alma Chilena" y las notas campesinas de "Teodorinda" y "Entierro en el Campo". Esta incorporación de la realidad estará presente en Neruda, Pablo de Rokha, hasta en Gonzalo Rojas (de la Gẹneraçión del 38) en su "Miseria del Hombre"; su poẹmą 
"Carbón" o "He comido con los Burgueses", en que junto a los problemas de temporalidad, de angustia existencial, se incorporan elementos populares. Nos llaman vivamente la atención, en Nicanor Parra, las incorporacioncs de frases hechas a sus poemas. Baste señalar "Es Olvido": ... "Juro que no recuerdo ni su nombre..." o "el olor del café siempre es el mismo" en "Hay un Día Feliz". Asimismo, hemos escuchado los poemas de Mario Ferrero, en que junto a la bella metáfora, al juego poético, se incorpora la sátira a los avisos populares - "departamento para caballero solo" "se arrienda sin niños"-, a todo aquello que pesa sobre el hombre determinándolo. Pezoa Véliz impone asi una manera a través de medio siglo de ausencia. De ahi que sean, justamente, quienes han recibido su impacto los que realizan con más fervor su homenaje.

Luego se anuncia una revisión de Huidobro. Pero he dicho que escamotearé el análisis de la poesía en este breve recuento, por ser tema largo y discutible. Sólo una idea más: la última generación de jóvenes poetas se ha malogrado, en algunos aspectos, por la imposibilidad total de dar a conocer sus producciones. Aquí mismo nos hablan los poetas de sus muchas obras inéditas que guardan ajadas en sus bolsillos. Urge, pues, la realidad de la Editorial Universitaria, hermosa idea que se insinuara en el pasado Encuentro, y la necesidad de que las Municipalidades de las principales ciudades chilenas vayan a la creación de Premios Municipales, cuyo galardón consista en la edición de la obra.

Hablaba del criollismo en prosa. Medio siglo de criollismo basta para afirmar que existe una tradición creada y que si, en la actualidad, el criollismo está en crisis, no quiere decir que haya muerto. Solamente está a la búsqueda de nuevas orientaciones para superarse. Una elemental Cronologia del Criollismo bastaría para probar su aporte:

Augusto D'Halmar, “Juana Lucero" (1902); Baldomero Lillo, "SubTerra" (1904), "Sub-Sole" (1907); Eduardo Barrios, "Del Natural" (1907), "El Niño que Enloqueció de Amor" (1915), "Páginas de un Pobre Diablo" (1923); Fernando Santiván, "Palpitaciones de Vida" (1909), "En la Montaña" (1917); Joaquín Diaz Garcés, "Páginas Chilenas" (1907); Guillermo Labarca Hubertson, "Al Amor de la Tierra" (1906), "Mirando al Océano" (1911); Federico Gana, "Días de Campo" (1916), "Cuentos Completos" (1926); Carlos Acuña, "Capachito" (1921); Rafael Maluenda, "Escenas de la Vida Campesina" (1909), "Los Ciegos" (1913), "La Pachacha" (1915); Manuel J. Ortiz, "Cartas de la Aldea" (1908); Marta Brunet, "Montaña Adentro" (1923), "Bestia Dañina" (1926), "Don Florisondo" 
(1926); Luis Durand, "La Chabela" (1927), "Mal de Amor" (1928) "Tierra de Pellines" (1929), "Campesinos" (1932); Joaquín Edwards Bello, "La Cuna de Esmeraldo" (1918), "El Roto" (1920); Januario Espinoza, "La Señorita Cortés Monroy", "Un Viaje con el Diablo" (1930); J. Santos González Vera, "Vidas Mínimas" (1923), "Alhué" (1928); Mariano Latorre, "Cuentos del Maule" (1912), "Cuna de Cóndores" (1918), "Ully" (1923), "Chilenos del Maule" (1929); Ernesto Montenegro, "Cuentos de mi Tio Ventura" (1933); Manuel Rojas, "Hombres del Sur" (1926), "El Delincuente" (1929); Alberto Romero, "Un Infeliz" (1927), "La Tragedia de Miguel Orozco" (1929); Carlos Sepúlveda Leyton, "Hij'Una” (1934), "La Fábrica" (1935); Víctor Domingo Silva, "La Pampa Trágica" (1921); Lautaro Yankas, "La Risa del Pillán" (1927), "Flor Lumao" (1932) .

La segunda etapa del criollismo (1915 a 1930) muestra a los escritores más preocupados de su forma, con un mayor sentido estilístico. Traen aportes de interés que logran reforzar la corriente realista. Su predilección por los temas campesinos hizo incurrir a los críticos en el error de denominar a la escuela y a la tendencia criollista como campestre.

La segunda Guerra Mundial, la guerra con España y el advenimiento del Frente Popular significaron, en Chile, la eclosión de una nueva generación: la del 38, que otros han llamado del 40. Se caracteriza por un mayor sentido social. Ya no se canta al individuo, sino a su exposición colectiva. Don Ricardo A. Latcham los califica como "Neocriollistas"; luego él mismo -según lo hace notar Mario Ferrero en un interesante ensayo sobre el criollismo en Chile, inédito- destaca el nacimiento de una "Epica Social". Nicomedes Guzmán con "La Sangre y la Esperanza" (1943); Andrés Sabella con "Norte Grande"; Daniel Belmar con "Roble Huacho" (1947) y luego "Coirón" (1950); Rubén Azócar con "Gente en la Isla" (1939), y Nicasio Tangol con "Huipampa, tierra de Sonámbulos" (1944); Reinaldo Lomboy, que publica el discutido "Ranquil" (1941); Volodia Telteiboim y su "Hijo del Salitre"; Gonzalo Drago, "Surcos" (1948); Baltazar Castro, "Cobre" (1941) y Oscar Castro, "Llampo de Sangre" (1950); Juan Godoy, "Angurrientos" (1940) ; Francisco Coloane, "Golfo de Penas" (1945) , "Cabo de Hornos" (1941); Luis González Zenteno, "Caliche" (1954) .

Se ha pretendido hacer una parcelación del criollismo en la Historia de la Literatura Chilena, de Hugo Montes y Orlandi; se habla allí de "criollismo rural y paisajista", "criollismo humanizado y psicológico", "criollismo tendencioso", "indianista", "Popular", "insular", "austral", etc.

Tal parcelación es antojadiza y falsa. No es posible realizar una clasi- 
ficación geográfica en un país como el nuestro, múltiple y extenso; todo ello va en desmedro de la unidad de lo nacional que se persigue.

Los Parricidas.-En Argentina, la generación joven se dio a conocer atacando a la generación anterior. El uruguayo Rodríguez Monegal los denominó "Los Parricidas". En nuestro país, la generación del 52 partió como el resultado de una fuerte crítica a la generación pasada. Esta generación surgió de la postguerra -crisis del descontento-, es contemporánea de la Bomba Atómica. Muchos de sus componentes han viajado, han hecho estudios universitarios; poseen, por tanto, una vasta cultura que ha estado en contacto con las últimas corrientes europeas. Hay una gran preocupación formal esteticista y pueden señalarse dos corrientes: una que va por la senda de la superación del realismo, con temas urbanos, lenguaje esencial e intencionado. Otra, que recurre a deformar la realidad, con temas patológicos, intentando crear prototipos falsos, en un afán meramente esteticista y evasionista.

Se destacan en la Generación del 52, Cladio Giaconi ("La Díficil Juventud", 1954); Herbert Müller ("Perceval”, 1954); Armando Cassigoli ("Confidencias y otros cuentos", 1954); Juan Donoso; Guillermo Atías ("El Tiempo Banal", 1955); José Manuel Vergara ("Daniel y los Leones Dorados", 1956); Carlos León (“Sobrino Unico", 1954); Alfonso Echeverría ("La Vacilación del Tiempo", 1957); José Donoso ("Veranco”, 1955). “Coronación" (1957), de José Donoso, aunque una obra un tanto amarga, señala uno de los aportes novelísticos de mayor interés, con lenguaje funcional y de factura realista. Tanto Donoso, como otros representantes de esta generación, más que el verbo crear - para realizar una novela-, prefieren el verbo "construir", con lo que señalan que la mera improvisación en una obra de arte corresponde al pasado.

Alfonso Echeverría intenta, en "La Vacilación del Tiempo", una obra de carácter filosófico; pero su desarrollo no convence.

Párrafo aparte merece Carlos León. En "Las Viejas Amistades" realiza una novela ajustada, de cuidadoso estilo, apropiada en el carácter de sus personajes, realista en su concepción y dotada de un clima sutilmente poético, mezclada a un fino humorismo que sólo encontramos en Jorge Edwards ("El Patio").

María Elena Gertner no convence con su novela "Islas en la Ciudad" (1958). Muestra una parcela social snobista, intentando crear falsos prototipos, especialmente en mujeres que lindan con las muchachas de tipo 
"saganesco". Se muestra una sociedad aristocrática que no corresponde a su representativa realidad: perversiones sexuales, quiebra del hogar, situaciones ilógicas. Una muchacha se enamora de un hombre casado por snobismo, porque está de moda. Luego se suicida. Si no convence su amor, menos convence sus suicidio.

José Manuel Vergara realiza, con "Daniel y los Leones Dorados", una de las mejores novelas chilenas de tipo europeo; pero una mediocre novela europea. Con el propósito de darle universalidad, ambienta su obra en la antítesis de dos culturas: Inglaterra y España. La obra resulta "desengagé", es decir, desenraizada. Cuando intenta un ambiente nacional en "Cuatro Estaciones" (1958) su éxito decrece. Su personaje es falso, pues no se justifica su desambientación, ni sus actitudes, ni menos ese adolescente de "semilla de maldad" es un prototipo. Su estilo se reseca y pierde los matices que, justamente, hacen una obra de arte.

Esto no quiere decir que la nueva generación no haya traído aportes valiosos. Existen escritores de mérito que realizarán la novela de nuestro tiempo.

Todavia algo más sobre esta generación para precisarla. Uno de sus representantes, Claudio Giaconi, nos ha expresado: "Antes de 1950, los nuevos escritores - algunos ya populares hoy día- eran seres anónimos. A falta de otra ocupación más interesante, viviamos entregados a una bohemia frenética y desesperada. Los escritores maduros no tocaban nuestra sensibilidad, no teníamos nada que aprender de ellos, pues permanecían engolfados en asuntos que la juventud ya no vivia". En anteriores declaraciones, Giaconi expresó: "Creemos que nuestra generación posee mayor cultura, sensibilidad y penetración psicológica que la generación anterior. Estimamos, por lo tanto, que somos más inteligentes que quienes nos precedieron y podemos realizar una mejor labor".

Tiene razón en muchos aspectos. Sólo una leve discrepancia. Ponemos en duda la jactanciosa aseveración de mayor inteligencia, sin desconocer que, generacionalmente, han aportado una corriente valiosa, que mantiene en buen pie nuestra literatura nacional con una afirmación y superación del realismo.

Ya vendrá, en su oportunidad, la revalidación de autores que contribuyeron a la fijación de nuestra nacionalidad. Como Mariano Latorre, a pesar de los defectos que puedan señalársele. Sin duda, esta revisión la hará la nueva promoción de críticos y comentaristas literarios - muchos de ellos formados en la Universidad con Ricardo Latcham- (Cedo- 
mil Goic, Germán Sepúlveda, Ricardo Benavides, Sergio Latorre, Pedro Lastra, el que ha escrito estas líneas - sólo por nombrar algunos-).

Por último, hago presente que estas desmañadas notas no tienen otro propósito que dejar constancia de los problemas para que el público lector que nos ha acompañado nos ayude a resolverlos y que los escritores se vayan con la conciencia de que han tocado puntos vitales en este valioso Segundo Encuentro Nacional de Escritores.

José Miguel Vicuña

\section{ANTECEDENTES DEL MOVIMIENTO INTELECTUAL DE CHILE DESDE LA GUERRA DEL PACIFICO HASTA 1920}

(Notas para un ensayo).

Señoras y señores:

ANTE TODO, quiero agradecer a la Universidad de Concepción, a su Rector, mi distinguido amigo don David Stitchkin y, especialmente, al Director de las Escuelas de Invierno de Chillán, el gran poeta y cultísimo profesor, el amigo recto y cordial, Gonzalo Rojas Pizarro, la extraordinaria experiencia de este Segundo Encuentro de Escritores, que, con el anterior y los que han de seguirle, han de constituir una de las poderosas e insustituibles palancas promotoras del interés, del desarrollo y del afinamiento cultural de todos los públicos de Chile y su incorporación al área viva de la poesía, del pensamiento y del arte, porque además de estrechar los lazos entre los escritores y permitir el debate limpio y esclarecedor, de ideas que pueden ser de importancia trascendental en un momento dado del proceso nacional o mundial, estos Encuentros proyectan en el público y aún en los ausentes, las corrientes universales del sentir, del pensar y del hablar, de ese mundo superior, que es el espiritu, que mueve a los hombres, a las máquinas y a los montes.

Y quiero confesar la emoción con que he visto la asistencia impresionante y fervorosa del público de Chillán a estas jornadas.

Finalmente, y antes de iniciar mi exposición, diré en dos palabras que clla es una ordenación apresurada de las notas para un ensayo que me propuse escribir hace un año y que sólo en pañales y en aspectos fragmentarios he ido abordando, desordenada y esporádicamente, entre otros escritos y trabajos y faenas de diversa indole. Espero que estas breves notas que daré a conocer sirvan de estimulo para quienes estén en mejores 